\title{
The Effect of Wet Cupping on Baroreceptor Sensitivity in Hypertensive Patients in Sidenreng Rappang Regency, South Sulawesi
}

\author{
Fadli Fadli ${ }^{1 *}$ D , Sumbara Sumbara ${ }^{2}$, Arabta M. Peraten Pelawi ${ }^{3}$, Suratun Suratun ${ }^{4}$, Rohandi Baharuddin ${ }^{5}$ \\ ${ }^{1}$ Department of Nursing, Muhammadiyah Sidrap Institute of Health and Science Technology, South Sulawesi, Indonesia; \\ ${ }^{2}$ Department of Nursing, Bhakti Kencana University, Bandung, Indonesia; ${ }^{3}$ Department of Nursing, STIKES Medistra Indonesia, \\ Bekasi, Indonesia; ${ }^{4}$ Department of Nursing, IKesT Muhammadiyah Palembang, Palembang, Indonesia; ${ }^{5}$ Department of \\ Nursing, Politeknik Kaltara, Tarakan, Indonesia
}

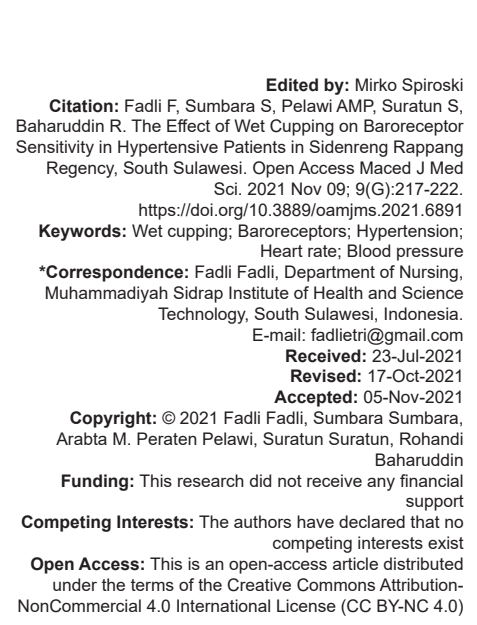

\section{Introduction}

Hypertension increases the prevalence of cardiovascular diseases [1]. Indonesia is one of the countries containing the most hypertensive patients [2] with a prevalence of $24.4 \%$ in $2008,25.8 \%$ in 2013 and increasing in 2018 by $34.1 \%$ [3]. Therefore, it is potentially higher than the available data. Patients with hypertension can attenuate baroreceptor stimuli [4], an autoregulatory system regulating heart rate and blood pressure located in the carotid sinuses of the aorta which stimulates efferent autonomic nerve activity to the heart and other blood vessels [5].

Increased baroreceptor sensitivity increases sympathetic and parasympathetic activity, and it results in a decrease of heart rate and blood pressure. Meanwhile, decreased baroreceptor sensitivity will cause an increase in blood pressure [6]. This sensitivity may influence the increasing prevalence of hypertension and cardiovascular diseases [7]. Therefore, a nonpharmacological action or therapy is needed to lower blood pressure in hypertensive patients.

One of complementary therapy is using the wet cupping method, a traditional treatment [8]. Research from Saudi Arabia stated that wet cupping therapy reduces systolic blood pressure effectively in hypertensive patients for about 4 weeks, without any serious side effect [9]. Another previous research stated that the location of the cupping point in the treatment of hypertension only focuses on two points [10]. In addition, some previous research results show that no one discussed specifically the increase in baroreceptor sensitivity by looking at indicators of blood pressure and heart rate.

Other researches stated there are six theoretical effects produced by cupping therapy. The reduction in pain levels is explained by "Pain-Gate 
Theory," "Diffuse Noxious Inhibitory Controls," and "Reflex zone theory." Furthermore, muscles relaxation, changes in local tissue structure, and increased blood circulation is explained by the "Nitric Oxide theory." The immunological effect is explained by "Activation of the immune system theory." Toxins release, waste, and heavy metals removal are described by "Blood Detoxification Theory" [11]. None of these theories has discussed the problem of increasing baroreceptor sensitivity. Therefore, this research aims to determine the effect of wet cupping therapy on increasing baroreceptors sensitivity in hypertensive patients.

\section{Methods}

This research was conducted in Sidenreng Rappang Regency, South Sulawesi, Eastern Indonesia from February to May 2021 and a Randomized Controlled Trial design. Before data collection, an approval was obtained from the Research Ethics Commission of STIKES Muhammadiyah Sidrap (No.426/KEP/II.3.AU/F/2021), using ethical principles by requesting prior informed consent from respondents. Two groups were involved, namely, the intervention group that received wet cupping therapy in addition to anti-hypertensive drugs, and the control which only received anti-hypertensive drugs.

The respondents were those who suffering from Grades I and II hypertension. The sample met the criteria when they had high blood pressure (systolic and diastolic blood pressure $\geq 140 \mathrm{mmHg}$ and $\geq 90 \mathrm{mmHg}$, respectively), ages between 25 and 50 years, and were male. Those having Grade III hypertension (systolic and diastolic blood pressure of $180 \mathrm{mmHg}$ and 110 or more), a complicating disease such as DM, and an additional hypertension risk according to hypertension management guidelines (WHO) were excluded from the study.

Wet cupping therapy procedure, namely, measures blood pressure, prepare wet cupping equipment (handsoon, mask, apron, cuppings, cupping pump, lancing, lancet, tray, com, sterile gauze, scissors, and herbal oil), clean the area using herbal oil and put a header then suction for 3-5 min, do a lancing device injury then put the header back on and suction. After 3-5 min open header, wipe around clamped area Wet cupping therapy is carried out at three points on the body. The first point is located 2 fingers posterior to the corners of the lower jaw on either side, just below the skull bone at the hairline (Al-Akhda'ain). The second point is the upper part of the spine that extends to the neck, at the sixth vertebrae or $\mathrm{C} 7$ cervical spine (Al-Kaahil). Another point is on both sides of the shoulder blade (Azh-Zahrul A'la). In this research, wet cupping therapy was carried out once a month for 3 consecutive months on the $17^{\text {th }}, 19^{\text {th }}$, and $21^{\text {st }}$ of the Arabic calendar (Hijri).

The results were blood pressure, pulse measurements and the measurement of arterial baroreflex sensitivity, which is the magnitude of the change in the RR interval when the systolic blood pressure changes. Each measurement was taken in a seated position using a digital oscillometric sphygmomanometer and watched in seconds to minimize biased results. Measurement of blood pressure and pulse was carried out after the wet cupping therapy, then screening every week to determine the average value of the decrease in blood pressure and pulse rate to determine the maximum daily limit for the effect of cupping therapy on blood pressure. Based on the guidelines, patients were advised to rest 3-5 min after receiving wet cupping therapy and then carry out blood pressure and pulse measurements in the arm during the initial visit. They were also advised not to consume foods containing nicotine or caffeine for $1 \mathrm{~h}$ before measuring blood pressure. Measurement results were recorded to be documented at least twice per visit. In addition, visits schedule was once a week for the next 8 weeks.

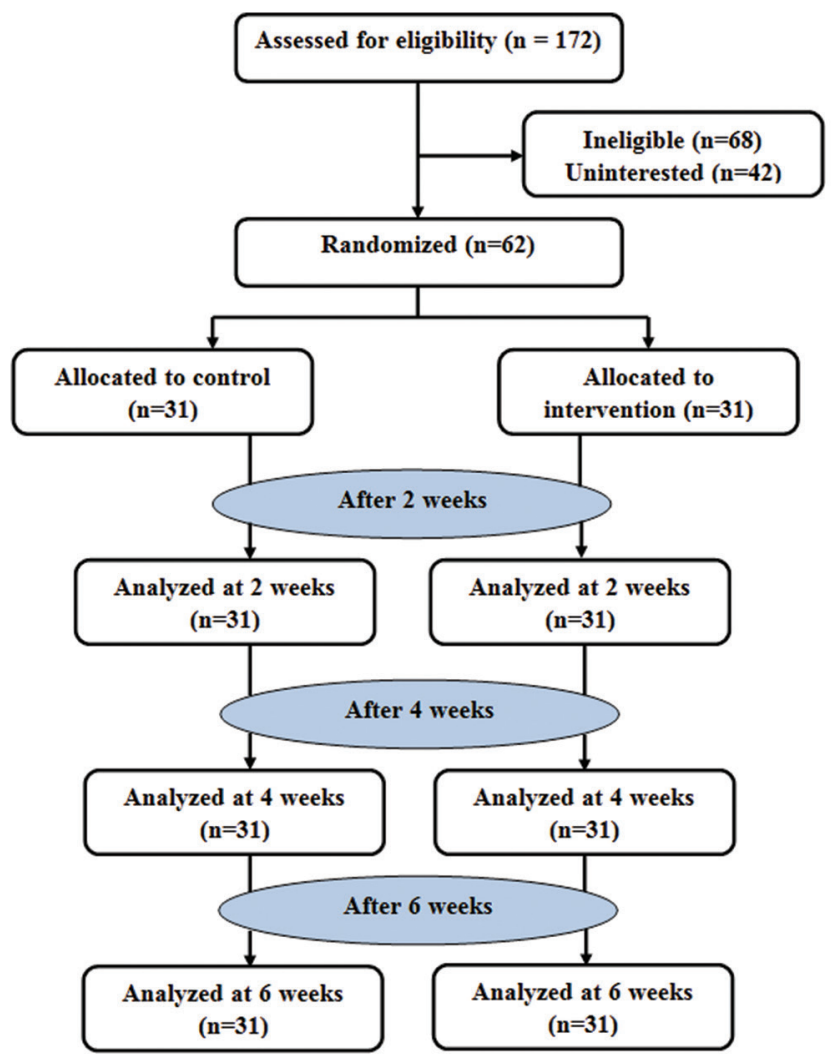

Figure 1: Flowchart of research sample recruitment

The wet cupping therapy has potential side effects according to the previous researches, which was evaluated at 2 and 4 weeks after the procedure. An electrocardiogram (ECG) was used to record 30 beats at a speed of $50 \mathrm{~mm} / \mathrm{s}$ before and after cupping therapy $\left(2^{\text {nd }}, 4^{\text {th }}\right.$, and $6^{\text {th }}$ weeks $)$ to measure the sensitivity of the arterial baroreflex. Meanwhile, all actions were recorded 
on the computer and ECG paper, and the RR interval distance was calculated using a Mitutuyo micrometer. The value was obtained after conducting a comparison of the RR interval with systolic blood pressure from an interval of 20 beats, until there was a decrease in the lowest systolic blood pressure after cupping therapy.

Hypertensive patient's number as a population was 172 respondents subjected to the feasibility test. This was filtered based on the research criteria, 68 people were excluded, and 42 refused to participate. Therefore, the remaining 62 were sampled and randomized into intervention and control groups of 31 people each. All the respondents engaged in every follow-up stage after wet cupping therapy for 2, 4, and 6 weeks in both groups (Figure 1).

Statistical analysis was performed using the SPSS version 21.0 program. Blood pressure comparisons were carried out in both groups from the commencement of measurement, to 2 and 4 weeks after the intervention using the paired t-test. A second blood pressure comparison was also performed with $p<0.05$ which was considered significant and the differences in mean blood pressure had a confidence interval of $95 \%$.

Based on the comparison between the control and intervention groups, there was no difference in the respondents' characteristics with $p<0.05$. Furthermore, the mean age was between 43 and 39 years or middle age group and had a hereditary history of heart disease. The LDL value showed that the average cholesterol was moderate, and physical activity was also lacking. Therefore, this result has a homogeneity value between both groups (Table 1).

Table 1: Comparison of characteristics in each group $(n=62)$

\begin{tabular}{llll}
\hline Characteristics & Control group & $\begin{array}{l}\text { Intervention } \\
\text { group }\end{array}$ & $\mathrm{p}^{*}$ \\
\hline Mean age, years ( \pm SD) & $43.0 \pm 6.8$ & $39.3 \pm 9.1$ & 0.146 \\
Mean Length of suffering from hypertension, & $6.9 \pm 1.8$ & $6.6 \pm 1.6$ & 0.559 \\
ratio ( \pm SD) & & & \\
Mean low-density lipoprotein, $\mathrm{mg} / \mathrm{dL}( \pm \mathrm{SD})$ & $152.3 \pm 14.2$ & $158.7 \pm 16.4$ & 0.241 \\
Family history of heart disease, $\mathrm{n}(\%)$ & $24(38.7)$ & $29(46.8)$ & 0.152 \\
History of smoking, $\mathrm{n}(\%)$ & $17(27.4)$ & $18(29.1)$ & 0.437 \\
Physical activity, $\mathrm{n}(\%)$ & $15(24.2)$ & $13(21.0)$ & 0.214 \\
\hline SD: Standard deviation, LDL: Low density lipoprotein. & & &
\end{tabular}

\section{Results}

Respondents in the intervention group after receiving the wet cupping therapy did not have serious side effects. Most of them had mild side effects only after a few hours, namely cupping location pain which did not exceed $48 \mathrm{~h}$. Furthermore, at 2 weeks, little number of respondents felt dizzy, headache, weakness, and drowsiness. At 6 weeks after therapy, some still experienced headaches and dizziness due to their lifestyle, physical activity, and smoking history which they did not control. The side effects for scar infection were not visible during the 2-6 weeks follow-up process (Table 2).
Table 2: Frequency of side effects incidence from wet cupping therapy during the period $(n=62)$

\begin{tabular}{|c|c|c|c|c|c|}
\hline \multirow{2}{*}{ Side effects } & \multicolumn{3}{|c|}{ After the wet cupping treatment } & \multirow[t]{2}{*}{ Total frequency } & \multirow[t]{2}{*}{ Percentage } \\
\hline & 2 weeks & 4 weeks & 6 weeks & & \\
\hline Cupping location pain & 3 & 0 & 0 & 3 & 9.5 \\
\hline Weak and sleepy & 6 & 1 & 0 & 7 & 21.4 \\
\hline Headache & 1 & 0 & 7 & 8 & 38.1 \\
\hline Suction cup-head & 21 & 0 & 0 & 21 & 76.2 \\
\hline Dizzy & 3 & 0 & 5 & 8 & 38.1 \\
\hline
\end{tabular}

Baroreceptor sensitivity in hypertensive respondents has a visible difference from lowering blood pressure's mean value. Based on the BP systolic indicator before and after a follow-up of 2-4 weeks, there was a significant difference in the elderly based on paired t-test $(p=0.000)$. This result is different from the measurement after 4 and 6 weeks which indicated no significant difference in systolic BP ( $p=0.248)$ (Table 3$)$. Consequently, the systolic BP at week 4 was within normal limits at week 6 . However, a mean increase of $1.62 \mathrm{mmHg}$ was discovered in the 6-week follow-up period, therefore, the effect limit of wet cupping therapy was only up to week 4 (Table 3).

Table 3: Comparison of baroreceptor sensitivity to blood pressure indicators after 2-6 weeks of wet cupping therapy

\begin{tabular}{|c|c|c|c|c|}
\hline $\begin{array}{l}\text { Difference in measurement } \\
\text { results }(n=31)\end{array}$ & $\begin{array}{l}\text { Mean difference } \\
\pm S D\end{array}$ & Min-Max (Cl95\%) & $\mathrm{t}$ & $\mathrm{p}^{*}$ \\
\hline \multicolumn{5}{|l|}{ TD Systole $(\mathrm{mmHg})$} \\
\hline Before therapy $\rightarrow$ after 2 weeks & $22.17 \pm 7.01$ & $18.52-25.84$ & 14.72 & $<0.001$ \\
\hline After 2 weeks $\rightarrow$ after 4 weeks & $10.82 \pm 6.18$ & $8.0-12.65$ & 7.59 & $<0.001$ \\
\hline After 4 weeks $\rightarrow$ after 6 weeks & $-1.62 \pm 5.81$ & $-4.36-2.03$ & -1.34 & 0.248 \\
\hline \multicolumn{5}{|l|}{ TD Diastolic (mmHg) } \\
\hline Before therapy $\rightarrow$ after 2 weeks & $6.32 \pm 6.56$ & $3.05-8.03$ & 4.01 & 0.001 \\
\hline After 2 weeks $\rightarrow$ after 4 weeks & $9.27 \pm 7.14$ & $6.38-10.24$ & 6.54 & $<0.001$ \\
\hline After 4 weeks $\rightarrow$ after 6 weeks & $-0.37 \pm 6.38$ & $-3.65-3.08$ & -2.74 & 0.583 \\
\hline
\end{tabular}

Differences in the baroreceptor sensitivity on diastolic blood pressure indicators were also significantly different (paired-t-test). Based on the results of diastolic BP between before and after 2 weeks of wet cupping therapy, there was a significant difference $(p=0.000)$. This was applied to the values of diastolic BP measurement 2 and 4 weeks after the therapy, which had a significant difference $(p=0.000)$. The results differed from the 4 and 6 weeks of follow-up period, which showed no significant difference ( $p=$ 0.583). This is because the mean diastolic BP values at week 4 and 6 were already within normal limits, but there was an average increase of $0.37 \mathrm{mmHg}$ at week 6. Therefore, the limit for the effect of wet cupping therapy in increasing baroreceptors sensitivity to blood pressure indicators was found at 4 weeks after therapy in both systolic and diastolic BP (Table 3).

Table 4 shows that there is a significant difference in the baroreceptor sensitivity to the pulse frequency indicator (paired-t-test). Based on the pulse frequency results, there was a significant difference between before and after 2 weeks of wet cupping therapy $(p=0.009)$. The values of diastolic BP measurement at 2 weeks and 4 weeks after therapy had a significant difference $(p=0.016)$. Furthermore, the 4 and 6 weeks of follow-up period had a significant difference $(p=0.030)$. This was because the pulse frequency mean value from week 2 to 6 lies within 
Table 4: Comparison of the sensitivity of the baroreceptors to pulse rate indicators after 2-6 weeks of wet cupping therapy

\begin{tabular}{|c|c|c|c|c|}
\hline $\begin{array}{l}\text { Difference in measurement } \\
\text { results }(n=31)\end{array}$ & Mean difference \pm SD & Min-Max (C195\%) & $\mathrm{t}$ & $\mathrm{p}^{*}$ \\
\hline \multicolumn{5}{|l|}{ Pulse rate (times/minute) } \\
\hline Before therapy $\rightarrow$ after 2 weeks & $2.27 \pm 3.71$ & $0.63-3.92$ & 2.88 & 0.009 \\
\hline After 2 weeks $\rightarrow$ after 4 weeks & $2.0 \pm 3.57$ & $0.42-3.58$ & 7.59 & 0.016 \\
\hline After 4 weeks $\rightarrow$ after 6 weeks & $1.96 \pm 3.95$ & $0.21-3.70$ & 2.32 & 0.030 \\
\hline
\end{tabular}

normal limits, but there was an average decrease of 1.96 beats/min at week 6 . Therefore, the wet cupping therapy effect's limit in increasing baroreceptors sensitivity to pulse frequency indicators occurred until the 6-week after the therapy.

The mean value of baroreceptor sensitivity in the group before wet cupping therapy was conducted after 2 weeks. Table 5 showed the difference in the value of the $R R$ interval parameter, which is $1.65 \pm 1.54 \mathrm{~ms} / \mathrm{mmHg}(p \leq 0.001)$. The measurement group after 2 and 4 weeks showed an RR interval value of $0.34 \pm 1.79 \mathrm{~ms} / \mathrm{mmHg}(p=0.356)$. Therefore, wet cupping has an effect on increasing baroreceptor sensitivity with a value of the parameter interval $R R$ increased by $0.34 \mathrm{~ms} / \mathrm{mmHg}$. The group after 4 and 6 weeks had a significant difference ( $p \leq 0.001$ ), this indicates that the cupping effect has disappeared due to a decrease in baroreceptor sensitivity with an RR interval parameter value of $1.59 \mathrm{~ms} / \mathrm{mmHg}$. Therefore, the wet cupping on increasing arterial baroreflex had an effect which was very high at week 4 . This was conducted after therapy with an average RR interval of $8.26 \mathrm{~ms} / \mathrm{mmHg}$ (Normal $8 \mathrm{~ms} / \mathrm{mmHg}$ ).

Table 5: Comparison of baroreceptor sensitivity parameter values before and after wet cupping therapy through ECG recordings at $R R$ intervals $(\mathrm{ms} / \mathrm{mmHg})$

\begin{tabular}{|c|c|c|c|c|}
\hline $\begin{array}{l}\text { Differences in measurement } \\
\text { results }(n=31)\end{array}$ & $\begin{array}{l}\text { Mean difference } \\
\pm \text { SD }\end{array}$ & Min-Max (CI95\%) & $\mathrm{t}$ & $\mathrm{p}^{*}$ \\
\hline \multicolumn{5}{|l|}{ Interval RR ms/mmHg) } \\
\hline Before therapy $\rightarrow$ after 2 weeks & $1.65 \pm 1.54$ & $1.08-2.01$ & 5.38 & $<0.001$ \\
\hline After 2 weeks $\rightarrow$ after 4 weeks & $0.34 \pm 1.79$ & $0.34-0.98$ & 1.00 & 0.356 \\
\hline After 4 weeks $\rightarrow$ after 6 weeks & $1.59 \pm 2.03$ & $0.80-2.29$ & 4.25 & $<0.001$ \\
\hline
\end{tabular}

\section{Discussion}

The research showed a significant difference between the intervention and control groups baroreceptors sensitivity detected through a decrease in systolic bp of $10.02 \mathrm{mmHg}$, diastolic bp of $9.27 \mathrm{mmHg}$, and pulse frequency of 2.27 beats/min after 2 weeks of follow-up. After 6 weeks of follow-up, the wet cupping effect stopped and there was no significant difference in blood pressure in both groups. Meanwhile, there was a difference in pulse frequency from week 2 to 6 . These results are consistent with previous research that found a significant difference in systolic blood pressure values between the intervention and control groups after 2 weeks of follow-up [12]. Another Chinese research stated wet cupping lowers blood pressure at the $4^{\text {th }}$ week after therapy [13]. Therefore, it produces an effect lasting for 2-4 weeks but not applied to the pulse frequency.

In comparison, the results of blood pressure before wet cupping therapy were performed at a follow-up period of 2 and 6 weeks. There were significant differences in the intervention as well as in the control groups. However, the decrease in blood pressure was not very significant probably because the follow-up period was too short. The respondents are aware of their blood pressure results and therefore change their diet and daily lifestyle such as physical activity, as well as adhere to a low salt diet. Physical conditions greatly affect the increase in baroreceptors' sensitivity as an autoregulation to blood pressure or heart health [14]. Furthermore, the respondents showed $27.4 \%$ in the control group and $29.1 \%$ in the intervention group had a history of smoking and lack of physical activity.

An Arabian research carried out using the wet cupping therapy method and comparing blood pressure results before and after 2 months of the procedure showed a significant difference [15]. These differ from the current result which showed the initial period with the follow-up period after wet cupping therapy had an increased baroreceptors sensitivity at week 2 and blood pressure at week 4 was within normal limits. The week 6 had an increase of $1.62 \mathrm{mmHg}$ in systolic $\mathrm{BP}$ and $0.37 \mathrm{mmHg}$ in diastolic BP from normal limits at week 4 . Meanwhile, there is a difference in pulse frequency from week 2 to 6 . The wet cupping is used as an alternative therapy with a time limit effect of 4 weeks in maintaining the baroreceptors' sensitivity as blood pressure and pulse frequency regulators in hypertensive patients.

This research showed the average value of baroreceptor sensitivity in the group before wet cupping therapy after 2 weeks. Table 5 showed the difference in the RR interval parameter value, which is $1.65 \pm 1.54 \mathrm{~ms} / \mathrm{mmHg}(p \leq 0.001)$. The differences in the measurement group after 2 and 4 weeks showed an $R R$ interval value of $0.34 \pm 1.79 \mathrm{~ms} / \mathrm{mmHg}(p=0.356)$. This indicates that the effect of wet cupping has an effect on increasing baroreceptor sensitivity with an increased value of $0.34 \mathrm{~ms} / \mathrm{mmHg}$. Meanwhile, the group after 4 and 6 weeks had a significant difference ( $p \leq 0.001)$, which showed that the cupping effect had disappeared due to a decrease in baroreceptor sensitivity with an $R-R$ interval parameter value of $1.59 \mathrm{~ms} / \mathrm{mmHg}$. Therefore, the wet cupping on increasing arterial baroreflex was very high at week 4 after therapy with an average RR interval of $8.26 \mathrm{~ms} / \mathrm{mmHg}$ (Normal $8 \mathrm{~ms} / \mathrm{mmHg}$ ).

An ECG was used to record 30 beats at a speed of $50 \mathrm{~mm} / \mathrm{second}$ to measure the sensitivity of the arterial baroreflex 1 week after cupping therapy. In addition, all the actions were recorded on the computer and ECG paper, also the RR interval distance was calculated using a Mitutuyo micrometer. The value 
was obtained after conducting a comparison of RR interval with systolic blood pressure from 20 beats. This was carried out to obtain the lowest decrease in systolic blood pressure after cupping therapy [16]. The same procedure was conducted in the previous research, and the mean arterial baroreflex sensitivity of pre-PTCA and post-PTCA was $2.51 \pm 3.23 \mathrm{~ms} / \mathrm{mmHg}$ and $1.96 \pm 1.61 \mathrm{~ms} / \mathrm{mmHg}$. Statistically, the difference in this value was significant after nitrate drugs were administered $(p=0.035)$ [17].

The process of wet cupping therapy is carried out on every $17^{\text {th }}, 19^{\text {th }}$, and $21^{\text {st }}$ (hijria) selected based on Islamic literature [18]. Another research stated it is not carried out on any other days, other than the one recommended by Islamic literature once a month for 3 consecutive months [19]. Therefore, further research is needed to focus on the differences between certain days and other days of wet cupping therapy results for changes in blood pressure and Mean Arterial Pressure (MAP) in hypertensive patients.

Although wet cupping therapy affects the increase in baroreceptor sensitivity by reducing blood pressure and pulse rate indicators. This decrease is influenced by several factors, one of which is the amount of blood removed during suction [11]. However, the amount of blood removed was not measured, hence, the greater the blood clots number, the better the result [20]. The mechanism of wet cupping therapy removes toxins mixed with blood or oxidants from the body through the skin surface [21]. This increases blood flow and prevents atherosclerosis, thereby stimulating the baroreceptors sensitivity which provides a stimulus to the autonomic nerves (reduce the sympathetic nerves work). Therefore, inhibiting the vasomotor center which causes vasodilation, leading to decreased blood pressure and pulse frequency [22].

The mechanism of increasing baroreceptors sensitivity with decreasing blood pressure and pulse frequency through the effect of wet cupping therapy is explained in the "Taibah Theory." This theory states wet cupping therapy dries out intestinal and excess intravascular fluid, as well as harmful metallic substances [23]. Wet cupping also stimulates endogenous nitric oxide production and excretion of accumulated vasoactive substances and free radicals, which leads to reduced blood pressure measurements [24]. Therefore, this therapy is useful for preventing a decrease in baroreceptors sensitivity which stimulates blood pressure and pulse frequency increase.

In this research, wet cupping therapy is believed to be a safe and harmless action because it does not have serious side effects for hypertensive patients. The immediate side effects were only minor pain due to the use of the lancing device and pulling the header, but this did not last long and disappeared after 1-2 days. Another effect is, there is a scar that disappears over time, which is within 5-7 days. Dizziness, headache, and weakness were experienced by some respondents but these did not make them withdraw from participating because there were more positive effects they felt after the wet cupping therapy. The previous research stated that the side effects of wet cupping therapy are divided into local and systemic side effects [25].

This research has a good effect, one of which is controlling the respondent's condition after cupping therapy for up to 6 weeks of the follow-up period. The limitation found showed that it did not measure the number of blood clots per cupping cup at the points of Al-Akhda'ain, Al-Kaahil, and Azh-Zahrul A'la. This is different from previous research because it focuses on determining the sensitivity of the baroreceptor functioning as a regulating system for blood pressure and pulse frequency using the taibah theory approach. Therefore, these results are very useful for medical personnel in providing interventions related to the handling and prevention of increased blood pressure in hypertensive patients with wet cupping therapy which has an effect up to 4 week and provides a stimulus to increase baroreceptors in the carotid sinuses.

\section{Conclusion}

Wet cupping therapy effectively increases baroreceptors sensitivity which extends the RR interval, reduces blood pressure, and pulse frequency in hypertensive patients up to a limit of 4 weeks, without any serious side effects. Therefore, it deserves to be recommended as a therapy for the prevention of hypertension. Further research needs to pay attention to the number of blood clots per cupping cup and not use anti-hypertensive drugs simultaneously. Research development on the measurement of MAP is also recommended.

\section{Acknowledgment}

The author is grateful to the Muhammadiyah Sidrap Institute of Health and Science Technology and the Sidenreng Rappang Regency Government, South Sulawesi, Indonesia for providing research facilities and good environment.

\section{References}

1. Mills KT, Bundy JD, Kelly TN, Reed JE, Kearney PM, Reynolds K, et al. Global disparities of hypertension prevalence 
and control: A systematic analysis of population-based studies from 90 countries. Circulation. 2016;134(6):441-50. https://doi. org/10.1161/CIRCULATIONAHA. 115.018912

\section{PMid:27502908}

2. Christiani $\mathrm{Y}$, Byles JE, Tavener M, Dugdale P. Assessing socioeconomic inequalities of hypertension among women in Indonesia's major cities. J Hum Hypertens. 2015;29(11):683-8. https://doi.org/10.1038/jhh.2015.8

\section{PMid:25652531}

3. Turana Y, Tengkawan J, Soenarta AA. Asian management of hypertension: Current status, home blood pressure, and specific concerns in Indonesia. J Clin Hypertens (Greenwich). 2020;22(3):483-5. https://doi.org/10.1111/jch.13681 PMid:31680397

4. Albaghdadi M. Baroreflex control of long-term arterial pressure Dep Intern Med. 2007;14(4):212-25.

5. Lohmeier TE, lliescu R. The baroreflex as a long-term controller of arterial pressure. Physiology (Bethesda). 2015;30(2):148-58. https://doi.org/10.1152/physiol.00035.2014 PMid:25729060

6. Kazimierska A, Placek MM, Uryga A, Wachel P, Burzyńska M, Kasprowicz M. Assessment of baroreflex sensitivity using timefrequency analysis during postural change and hypercapnia. Comput Math Methods Med. 2019;2019:4875231. https://doi. org/10.1155/2019/4875231

PMid:30863454

7. Fu Q, Ogoh S. Sex differences in baroreflex function in health and disease. J Physiol Sci. 2019;69(6):851-9. https://doi. org/10.1007/s12576-019-00727-z

PMid:31721084

8. Aboushanab TS, AISanad S. Cupping therapy: An overview from a modern medicine perspective. J Acupunct Meridian Stud. 2018;11(3):83-7. https://doi.org/10.1016/j.jams.2018.02.001 PMid:29436369

9. Aleyeidi NA, Aseri KS, Matbouli SM, Sulaiamani AA, Kobeisy SA Effects of wet-cupping on blood pressure in hypertensive patients: A randomized controlled trial. J Integr Med. 2015;13(6):391-9. https://doi.org/10.1016/S2095-4964(15)60197-2 PMid:26559364

10. Elizabeth MA, Yusof YB, Bin Mohamad MS, Abu Bakar MF, Ibrahim MA. Efficacy of cupping in the treatment of hypertension disease using graph colouring. J Phys Conf Ser. 2019;1366(1):12044

11. Al-Bedah AM, Elsubai IS, Qureshi NA, Aboushanab TS, Ali GI, El-Olemy AT, et al. The medical perspective of cupping therapy: Effects and mechanisms of action. J Tradit Complement Med. 2018;9(2):90-7. https://doi.org/10.1016/j.jtcme.2018.03.003 PMid:30963043

12. Darmawan B, Fatmasari D, Sri R, Pujiastuti E. Negative air pressure on wet cupping in decreasing blood pressures in hypertensive patients. Nurse Med J Nurs. 2017;7(2):116-29.

13. Xing M, Yan X, Yang S, Li L, Gong L, Liu H, et al. Effects of moving cupping therapy for plaque psoriasis: Study protocol for a randomized multicenter clinical trial. Trials. 2020;21(1):229. https://doi.org/10.1186/s13063-020-4155-0

\section{PMid:32102679}

14. Subramanian SK, Sharma VK, Arunachalam V, Rajendran R, Gaur A. Comparison of baroreflex sensitivity and cardiac autonomic function between adolescent athlete and non-athlete boys-a cross-sectional study. Front Physiol. 2019;10:1043. https://doi.org/10.3389/fphys.2019.01043

PMid:31507430

15. Al-Tabakha MM, Sameer FT, Saeed MH, Batran RM Abouhegazy NT, Farajallah AA. Evaluation of bloodletting cupping therapy in the management of hypertension. J Pharm Bioallied Sci. 2018;10(1):1-6. https://doi.org/10.4103/jpbs.JPBS_242_17 PMid:29657501

16. La Rovere MT, Pinna GD, Raczak G. Baroreflex sensitivity: Measurement and clinical implications. Ann Noninvasive Electrocardiol. 2008;13(2):191-207. https://doi. org/10.1111/j.1542-474X.2008.00219.x PMid: 18426445

17. Tjahjono CT, Munawar M, Kaligis R, Idham I. Baroreflex sensitivity in patients with coronary artery disease who underwent percuteous coronary intervention. Indones $\mathrm{J}$ Cardiol. 2007;28(6):415-23

18. Qureshi NA, Ali GI, Abushanab TS, El-Olemy AT, Alqaed MS El-Subai IS, Al-Bedah AM. History of cupping (Hijama): A narrative review of literature. J Integr Med. 2017;15(3):172-81. https://doi.org/10.1016/S2095-4964(17)60339-X PMid:28494847

19. Zhang X, Tian R, Lam WC, Duan Y, Liu F, Zhao C, et al. Standards for reporting interventions in clinical trials of cupping (STRICTOC): Extending the CONSORT statement. Chin Med. 2020;15:10. https://doi.org/10.1186/s13020-020-0293-2 PMid:32021646

20. Lu S, Du S, Fish A, Tang C, Lou Q, Zhang X. Wet cupping for hypertension: A systematic review and meta-analysis. Clin Exp Hypertens. 2019;41(5):474-80. https://doi.org/10.1080/1064196 3.2018 .1510939 PMid:30183389

21. Kim JE, Cho JE, Do KS, Lim SY, Kim HJ, Yim JE. Effect of cupping therapy on range of motion, pain threshold, and muscle activity of the hamstring muscle compared to passive stretching. J Korean Soc Phys Med. 2017;12(3):23-32.

22. Joyce B, Jane H. Keperawatan Medikal Bedah: Manajemen Klinis Untuk Hasil Yang Diharapkan. $8^{\text {th }}$ ed. Singapore: Elsevier; 2014.

23. El-Shanshory M, Hablas NM, Shebl Y, Fakhreldin AR, Attia M, Almaramhy $\mathrm{HH}$, et al. Al-hijamah (wet cupping therapy of prophetic medicine) significantly and safely reduces iron overload and oxidative stress in thalassemic children: A novel pilot study. J Blood Med. 2018;9:241-51. https://doi.org/10.2147/ JBM.S170523

PMid:30588142

24. Almaiman AA. Proteomic effects of wet cupping (Al-Hijamah). Saudi Med J. 2018;39(1):10-6. https://doi.org/10.15537/ smj.2018.1.21212 PMid:29332103

25. Jadhav DK. Cupping therapy: An ancient alternative medicine J Phys Fit Med Treat Sport. 2018;3(1):1-4. 